\title{
Predictive Factors, 30-Day Clinical Outcomes, and Costs Associated with Cerebrospinal Fluid Leak in Pituitary Adenoma Resection
}

\author{
Adish Parikh ${ }^{1}$ Arjun Adapa ${ }^{1}$ Stephen E. Sullivan ${ }^{2}$ \\ ${ }^{1}$ Department of Otolaryngology Head and Neck Surgery, University \\ of Michigan, Ann Arbor, Michigan, United States \\ 2 Department of Neurosurgery, University of Michigan, Ann Arbor, \\ Michigan, United States
}

\author{
Erin L. McKean ${ }^{1,2}$
}

\author{
Address for correspondence Erin McKean, MD, MBA, Department of \\ Otolaryngology Head and Neck Surgery, University of Michigan, \\ 1500 E Medical Center Dr, Ann Arbor, MI, 48109, United States \\ (e-mail: elmk@med.umich.edu).
}

\begin{abstract}
Keywords

- endoscopic endonasal approach

- pituitary adenoma

- cerebrospinal fluid leak

- CSF leak

- costs

- complications

- pituitary surgery

Cerebrospinal fluid (CSF) leak is a complication of endoscopic endonasal pituitary adenoma resection. Previous studies examining complications of pituitary adenoma resection have not examined associations of an exhaustive list of clinical and financial variables with CSF leak. We designed a retrospective analysis of 334 consecutive patients that underwent endoscopic endonasal pituitary adenoma resection at a single institution over 5 years, analyzing associations between CSF leak and demographic data, operative data, comorbidities, clinical complications and outcomes, costs, charges, and payments. Of the 20 preoperative variables studied, none were positively associated with CSF leak in between-groups comparison, although multivariate analysis revealed an association with a history of radiation to the skull base (odds ratio [OR], 8.67; 95\% confidence interval [Cl], 0.94-57.03; $p<0.05$ ). CSF leak was associated with a significantly higher rate of postoperative diabetes insipidus $(\Delta=33.4 \%, p=0.040)$ and increased length of stay after operation in betweengroups comparison. Multivariate analysis on postoperative variables revealed significant associations between CSF leak and intracerebral hemorrhage (OR, 17.44; $95 \% \mathrm{Cl}$, $0.65-275.3 ; p<0.05)$ and postoperative intracranial infection (OR, 28.73; $95 \% \mathrm{Cl}$, 2.04-438.7; $p<0.05)$. Also, CSF leak was associated with significantly higher costs $(\Delta=\$ 15,643, p<0.05)$ and hospital charges $(\Delta=\$ 46,026, p<0.05)$. Operating room time, room and board, and supplies and implants were the strongest cost drivers. This study highlights the difficulty of utilizing preoperative variables to predict CSF leak, the clinical complications and outcomes of leak, and the financial subcategories that drive the costs, charges, and payments associated with this complication.
\end{abstract}

\section{Introduction}

The endoscopic endonasal approach is a common method for pituitary adenoma resection. Many studies have reinforced that the operation is safe with overall favorable postoperative outcomes relative to the microscopic approach. ${ }^{1-3}$ However, there are notable risks for complications such as diabetes

received

September 22, 2018

accepted after revision

January 11, 2019

published online

February 18, 2019

insipidus (DI), cranial nerve injury, and cerebrospinal fluid (CSF) leak, among others, that can lead to morbidity, mortality, and substantial financial costs.

One of the most common complications is CSF leak due to the intracranial maneuvering needed for the resection of pituitary tumors. ${ }^{4-6}$ Piek et al in Germany found a 5.36\% leak rate in their 168 patients, whereas Grotenhuis in the

(c) 2020 Georg Thieme Verlag KG Stuttgart · New York
DOI https://doi.org/ 10.1055/s-0039-1679896. ISSN 2193-6331. 
Netherlands found a $10.7 \%$ rate in 412 patients. $^{7,8}$ As discussed by Lobatto et al identifying patients with risk factors for complications like CSF leak is imperative for appropriate consideration of preoperative planning and timing of the operation, patient counseling, consultation or referral to a center of excellence, alternative treatments, and postoperative management such as short versus long stay. ${ }^{9}$

Some literature has identified risk factors for postoperative CSF leak. Nishioka et al suggest that prior transsphenoidal surgery and prior radiotherapy to the skull are risk factors, while Dlouhy et al and Ivan et al found that increased body mass index (BMI) was correlated with CSF leak. ${ }^{10-12}$ Lobatto et al conducted a systematic review on general endoscopic pituitary surgical outcomes and identified 14 studies that examined risk factors for CSF leaks, specifically. ${ }^{9}$ Only interventricular extension was consistently associated with CSF leak, although extension was defined in different ways in different studies. Some studies have identified younger age, ${ }^{13,14}$ increased BMI, ${ }^{11,13,14}$ female gender, ${ }^{13,14}$ increased tumor size, ${ }^{15}$ and surgeons' learning ${ }^{16}$ curve as less consistent associations with CSF leaks. Again, differences in variable definitions make these comparisons difficult (e.g., age categories, tumor size categories, and learning curve).

From our literature review, there are no studies specifically examining clinical outcomes of CSF leak, such as mortality, 30-day emergency department (ED) visits, and associations with other complications, with the exception of one study noting that the length of stay (LOS) was twice as long in patients with CSF leakage. ${ }^{11}$ There is some research on the costs of CSF leak following endonasal endoscopic resection of pituitary adenoma. Piek et al noted that without CSF leak, costs were $€ 14,079.37$ per case with a reimbursement of $€ 14,856.05$ per case (net $+€ 780$ per case). The costs were increased in CSF leaks-€25,286.60/case with a reimbursement of $€ 25,499.39$ (net $+€ 210$ per case). ${ }^{7}$ It is not surprising that a complication like CSF leak leads to higher costs. To help alleviate this increased cost, it is helpful to identify the drivers of this cost so providers and administrators can help mitigate the financial burden. Cost drivers of CSF leak are currently poorly understood. A retrospective study of 27 patients that underwent pituitary adenoma resection found that total operating room (OR) and total bed-assignment costs constituted the highest expense, representing more than $60 \%$ of the cost of hospitalization. ${ }^{17}$ Because CSF leak has been shown to be associated with longer LOS and has the potential for reoperation, these cost drivers may be the biggest sources of increased cost in CSF leak patients, although this has not been specifically studied.

Despite the prevalence of postoperative CSF leak in endoscopic endonasal pituitary surgery, many studies into the risk factors for CSF leak appear to assess singular factors, such as BMI or prior pituitary operation, rather than exploring an exhaustive list of demographic data and comorbidities within a large set of patients. In addition, there is limited literature on the cost drivers of postoperative CSF leak in this patient group, particularly in the United States, and 30-day postoperative outcomes in these patients.
The main objective of our study was to create a large database of patient-specific variables, as well as postoperative outcomes and costs to better understand the causes and results, both clinically and financially, of CSF leak. Identification of those at risk for CSF leak could potentially change perioperative management. In addition, because previous studies have had controversial conclusion on risk factors of CSF leak, we hope that our study can better clarify the impact of these variables (i.e., gender, BMI, and tumor size). Also, due to the breadth of the variables in our database, we hope to study potential risk factors and associations with CSF leak that have not been previously studied (i.e., medical comorbidities and 30-day postoperative outcomes) and to create a more robust multivariate linear regression analysis. Lastly, understanding cost and charge data may allow quantification of the financial impact of CSF leak via specific cost drivers, allowing us to pinpoint specific variables that hospitals may focus their efforts on to minimize costs of CSF leak and optimize value of the operation.

\section{Methods}

We designed a retrospective analysis on 334 consecutive patients that underwent endoscopic endonasal pituitary adenoma resection at the University of Michigan by the single team of senior authors from March 2011 to March 2016. Patients with craniopharyngiomas or Rathke's cleft cyst and patients that underwent concomitant or early staged craniotomy (i.e., for intracranial hemorrhage at presentation unrelated to the pituitary adenoma, sellar masses biopsied endoscopically but resected via craniotomy or giant adenomas requiring planned multistaged approaches) were not included in this study. Using our secure internal health system self-service data search tool, demographic data including age, sex, and race was collected. Next, a search on this cohort using a text-recognition tool, Electronic Medical Record Search Engine (EMERSE), allowed for collection of operative data, comorbidities, and clinical complications/outcomes. ${ }^{18}$ EMERSE allowed us to search for "word bundles" in a patient's chart to find matching words and phrases. A word bundle included several synonyms for the variable of interest. After identifying matches, the corresponding clinical note was reviewed for confirmation of the variable (i.e., patient has a history of myocardial infarction in their preoperative note). Preoperative variables are shown in -Table 1 and postoperative variables, including complications and outcomes, are shown in - Table 2. The vast majority of variables were binary or categorical (i.e., patient did or did not have a stroke in the postoperative period). Only postoperative data within 30 days of the operation date was collected.

Financial data on our cohort, including total hospital costs (what it costs internally to provide the care, allocated directly and indirectly), charges (the price tag to the payor for hospital and professional services), and payments (what we are actually paid for our care) for the hospital billing encounters associated with the pituitary operations, was collected via the Michigan Medicine Corporate Finance 
Table 1 List of preoperative variables measured, definitions, and variable conditions. A total of 20 variables were measured and 14 of these are comorbidities

\begin{tabular}{|c|c|c|}
\hline Variable name & Definition & Conditions of the variable \\
\hline Age & Date of operation minus date of birth & Linear: 0-infinity \\
\hline Gender & Gender & Male, female, NA \\
\hline Race & White, Black, Hispanic, or other race & White, Black, Hispanic, or other race \\
\hline Tumor type & $\begin{array}{l}\text { Primary type of pituitary tumor based on } \\
\text { pathology }\end{array}$ & $\begin{array}{l}\text { Nonsecreting, prolactinoma, acromegaly, } \\
\text { Cushing's disease, TSH-oma }\end{array}$ \\
\hline Macroadenoma & Tumor size $>1 \mathrm{~cm}$ & Yes, No, NA \\
\hline $\mathrm{H} / \mathrm{o} \mathrm{Ml}$ & $\begin{array}{l}\text { History of past myocardial infarction prior to } \\
\text { operation }\end{array}$ & Yes, No, NA \\
\hline $\mathrm{H} / \mathrm{o} \mathrm{CHF}$ & $\begin{array}{l}\text { History of past congestive heart failure prior to } \\
\text { operation }\end{array}$ & Yes, No, NA \\
\hline $\mathrm{H} / \mathrm{o}$ stroke & History of past stroke prior to operation & Yes, No, NA \\
\hline Preop visual field cut & $\begin{array}{l}\text { Field cut (no light) within } 1 \text { month prior to } \\
\text { surgery }\end{array}$ & Yes, No, NA \\
\hline $\begin{array}{l}\text { Preop decreased } \\
\text { visual acuity }\end{array}$ & $\begin{array}{l}\text { Decreased visual acuity prior to surgery } \\
\text { (uncorrectable via eye glasses or contacts) }\end{array}$ & Yes, No, NA \\
\hline H/o pulmonary disease & $\begin{array}{l}\text { Chronic lung disease requiring maintenance } \\
\text { medications }\end{array}$ & Yes, No, NA \\
\hline Diabetes mellitus & Diabetes mellitus diagnosis prior to operation & Yes, No, NA \\
\hline Renal disease & CKD stage 3 or higher & Yes, No, NA \\
\hline Liver disease & Liver disease diagnosis prior to operation & Yes, No, NA \\
\hline Blood thinners & $\begin{array}{l}\text { Use of aspirin, warfarin, dabigatran, apixaban, } \\
\text { rivaroxaban, clopidogrel, or heparin noted in } \\
\text { pre-op history and physical }\end{array}$ & Yes, No, NA \\
\hline $\mathrm{H} / \mathrm{o}$ radiation to skull base & Radiation therapy to the skull prior to operation & Yes, No, NA \\
\hline H/o prior pituitary surgery & Pituitary surgery prior to operation & Yes, No, NA \\
\hline Immune suppression & $\begin{array}{l}\text { Chronic immune suppression including current } \\
\text { (within } 30 \text { days preop) chemotherapy; } \\
\text { autoimmune disease or transplant requiring } \\
\text { immunosuppressants, or a diagnosis of primary } \\
\text { immunodeficiency }\end{array}$ & Yes, No, NA \\
\hline BMI & Body mass index & Linear 0 -infinity \\
\hline Obesity & $\mathrm{BMI}>30 \mathrm{~kg} / \mathrm{m}^{2}$ & Yes, No, NA \\
\hline
\end{tabular}

Abbreviations: CKD, chronic kidney disease; CHF, chronic heart failure; MI, myocardial infarction; TSH, thyroid-stimulating hormone.

Office. These data, further defined in - Table 3, encompass expenses from the admission date through the discharge date, up to and including 30 days postoperatively. In addition, these financial metrics were subdivided for each patient in our cohort by subcategory (e.g., anesthesia, OR time, and supplies/implants).

Of the 334 patients, 13 patients were found to have had a postoperative CSF leak within 30 days of operation. We stratified our database into two different groups: "CSF leak group" ( $n=13)$ and "non-CSF leak group" $(n=321)$. This allowed us to compare the variables shown in -Tables 1 and $\mathbf{2}$ between these two groups to identify significant differences. Due to unequal sizes of the two groups, a twotailed $t$-test assuming unequal variances was utilized to compare variables. To our knowledge, this is the most extensive set of clinical variables collected to analyze relationships with CSF leak in patients that underwent pituitary adenoma resection. There are 20 preoperative variables, 15 postoperative complications (not including requirement of desmopressin for DI and type of CSF leak intervention), and 6 surgical outcome variables. To evaluate the relative contributions and associations of certain preoperative, operative, demographic, postoperative clinical and surgical variables to CSF leak, univariate logistic regression was performed for each variable against CSF leak. All variables with $p<0.2$ were included in a multivariate logistic regression. We considered a two-sided $p<0.05$ to be statistically significant. Data were analyzed using R Version 3.5.2 and R Studio 1.1.456.

Lastly, total costs and drivers were compared between the two groups. Average total hospital costs, charges, and payments were calculated for the CSF leak group and non-CSF leak group. To calculate the average net profit for a CSF leak patient, average hospital cost was subtracted from average 
Predictive Factors, 30-Day Clinical Outcomes, and Costs Associated with CSF Leak in Pituitary Adenoma

Table 2 List of postoperative variables: Variables collected in the 30-day postoperative period, definitions, and variable conditions. The list is categorized into complications and clinical outcomes. Fifteen complications (and two interventions) and six clinical outcome variables were measured

\begin{tabular}{|c|c|c|}
\hline Variable name & Definition & Conditions of the variable \\
\hline \multicolumn{3}{|c|}{ Complication within 30 days postoperative } \\
\hline Diabetes insipidus & $\begin{array}{l}\text { A urine-specific gravity of } 1.005 \text { or less, a urine } \\
\text { osmolality less than } 200 \mathrm{mOsm} / \mathrm{kg} \text {, or physician } \\
\text { diagnosis in note }\end{array}$ & Yes, No, NA \\
\hline Desmopressin required & $\begin{array}{l}\text { Desmopressin required postoperative to treat } \\
\text { diabetes insipidus }\end{array}$ & Yes, No, NA \\
\hline CSF leak & Clinical diagnosis of a CSF Leak & Yes, No, NA \\
\hline CSF leak Intervention & What was used to treat CSF leak & $\begin{array}{l}\text { NA, surgery, lumbar drain, acetazolamide, } \\
\text { conservative management, MD }\end{array}$ \\
\hline Intracerebral hemorrhage & $\begin{array}{l}\text { Hemorrhage or hematoma requiring additional } \\
\text { scans or other interventions }\end{array}$ & Yes, No, NA \\
\hline Tension pneumocephalus & $\begin{array}{l}\text { Pneumocephalus confirmed on imaging and } \\
\text { causing compressive symptoms }\end{array}$ & Yes, No, NA \\
\hline Intracranial infection & $\begin{array}{l}\text { Clinical diagnosis or meningitis, cerebritis, or } \\
\text { abscess requiring intervention (including } \\
\text { delayed discharge for observation) }\end{array}$ & Yes, No, NA \\
\hline Decreased visual field & Visual field cut not present preoperatively & Yes, No, NA \\
\hline Decreased visual acuity & Decreased visual acuity as a result of surgery & Yes, No, NA \\
\hline Cranial nerve Injury & $\begin{array}{l}\text { New cranial neuropathy not present } \\
\text { preoperatively }\end{array}$ & Yes, No, NA \\
\hline $\mathrm{Ml}$ & $\begin{array}{l}\text { Clinical diagnosis of myocardial infarction based } \\
\text { on EKG and/or troponins }\end{array}$ & Yes, No, NA \\
\hline Stroke & Clinical diagnosis of stroke & Yes, No, NA \\
\hline DVT or PE & $\begin{array}{l}\text { Deep vein thrombosis or pulmonary embolism } \\
\text { diagnosis }\end{array}$ & Yes, No, NA \\
\hline Severe arrhythmia & $\begin{array}{l}\text { Arrhythmia in the postoperative period requir- } \\
\text { ing any intervention (new meds, delayed dis- } \\
\text { charge, cardioversion) }\end{array}$ & Yes, No, NA \\
\hline Hyponatremia & $\begin{array}{l}\text { Serum sodium level }<136 \mathrm{mEq} / \mathrm{L} \text { or diagnosis } \\
\text { in note }\end{array}$ & Yes, No, NA \\
\hline Hypernatremia & $\begin{array}{l}\text { Serum sodium level }>145 \mathrm{mEq} / \mathrm{L} \text { or diagnosis in } \\
\text { note }\end{array}$ & Yes, No, NA \\
\hline Respiratory failure & $\begin{array}{l}\text { Respiratory compromise requiring noninvasive } \\
\text { or invasive positive pressure ventilation }\end{array}$ & Yes, No, NA \\
\hline \multicolumn{3}{|c|}{ Clinical Outcomes within 30 days postoperative } \\
\hline Length of stay & $\begin{array}{l}\text { How many nights spent in the hospital after } \\
\text { surgery prior to initial discharge }\end{array}$ & Linear 0-infinity \\
\hline 30-day re-admission & $\begin{array}{l}\text { Readmission into Michigan Medicine or other } \\
\text { hospital prior to } 30 \text { days postoperative, as noted } \\
\text { within Michigan Medicine EMR }\end{array}$ & Yes, No, NA \\
\hline Total length of stay & $\begin{array}{l}\text { Total number of nights spent in hospital after } \\
\text { surgery, including all readmissions prior to } 30 \\
\text { days postoperatively }\end{array}$ & Linear 0-infinity \\
\hline 30-day ED visits & $\begin{array}{l}\text { Emergency department visit at Michigan Medi- } \\
\text { cine or any other ED, as noted within Michigan } \\
\text { Medicine EMR }\end{array}$ & Yes, No, NA \\
\hline 30-day reoperation & $\begin{array}{l}\text { Reoperation to treat CSF leak, remove residual } \\
\text { tumor, or to treat bleeding }\end{array}$ & Yes, No, NA \\
\hline 30-day mortality & Death after surgery & Yes, No, NA \\
\hline
\end{tabular}

Abbreviations: CSF, cerebrospinal fluid; EKG, electrocardiogram; EMR, electronic medical record; MI, myocardial infarction. 
Table 3 Definitions of financial metrics used in analysis

\begin{tabular}{|l|l|}
\hline $\begin{array}{l}\text { Financial } \\
\text { metric }\end{array}$ & Definition \\
\hline $\begin{array}{l}\text { Hospital } \\
\text { charges }\end{array}$ & $\begin{array}{l}\text { Sum of all charges sent to the patient/payor for } \\
\text { the services the hospital provides to the patient }\end{array}$ \\
\hline $\begin{array}{l}\text { Professional } \\
\text { charges }\end{array}$ & $\begin{array}{l}\text { Component of hospital charges; clinical } \\
\text { caregiver charges (e.g., physician, resident) } \\
\text { for a hospital billing encounter sent to the } \\
\text { patient/payor }\end{array}$ \\
\hline $\begin{array}{l}\text { Hospital } \\
\text { costs }\end{array}$ & $\begin{array}{l}\text { Total money that the hospital spends on a } \\
\text { patient's encounter; sum of direct and vari- } \\
\text { able costs for a hospital billing encounter }\end{array}$ \\
\hline $\begin{array}{l}\text { Hospital } \\
\text { direct } \\
\text { variable } \\
\text { costs }\end{array}$ & $\begin{array}{l}\text { Component of hospital costs. What the hos- } \\
\text { pital spends on worker supplies, patient care } \\
\text { supplies, diagnostic and therapeutic supplies, } \\
\text { and medications }\end{array}$ \\
\hline $\begin{array}{l}\text { Hospital } \\
\text { payments }\end{array}$ & $\begin{array}{l}\text { Insurance and patient payments received by } \\
\text { the hospital }\end{array}$ \\
\hline
\end{tabular}

hospital payment. Next, hospital charges, costs, direct variable costs (a component of total costs), payments, and professional charges (a component of total hospital charges) were then subdivided to a more granular level, which we call a "financial subcategory" or simply "subcategory," in the CSF leak group to examine the contribution of the subcategory to each variable. Of note, for one CSF leak patient treated in 2011 , encounter details by financial subcategory could not be obtained due to differences in data entry prior to 2012. As such, this patient was excluded from the financial analysis separated by subcategory $(n=12)$. Finally, to examine the cost of CSF leak interventions used in our CSF leak group, average hospital charges, costs, professional charges, and LOS were compared between patients treated with surgery alone, lumbar drain, or a combination of both. These data included all 13 patients in the CSF leak group.

\section{Results}

Our total cohort included 334 patients. Two-hundred patients (60\%) had nonsecreting pituitary adenomas. Of the 134 patients (40\%) with secreting tumors, acromegaly was the most common disease ( $n=77,23 \%$ ). Two-hundred eightytwo patients (84\%) were diagnosed with macroadenoma. The average age at operation was 52.96 years old, $55 \%$ of patients were male, and $83 \%$ of patients were white. Summary of tumor characteristics and demographics is shown in - Table 4.

\section{Significant Differences in Preoperative Variables}

After stratifying our total cohort for CSF leak ( $n=13,3.9 \%)$, we found several significant differences between the leak groups versus the nonleak group (-Table 5). There were four comorbidities that were significantly less common in the CSF leak group-history of congestive heart failure $(p<0.001)$, history stroke $(p=0.001)$, history of liver disease $(p<0.001)$, and immunosuppression $(p<0.001)$. Of the 13 patients with CSF leak, none had a history of any of these four conditions. Although the differences between the two groups were highly
Table 4 Tumor characteristics and basic demographics on 334 patients

\begin{tabular}{|l|l|l|}
\hline & Amount & Percentage of total \\
\hline Nonsecreting & 200 & $59.9 \%$ \\
\hline Secreting & 134 & $40.1 \%$ \\
\hline Acromegaly & 77 & $23.1 \%$ \\
\hline Cushing's disease & 41 & $12.3 \%$ \\
\hline Prolactinoma & 14 & $4.2 \%$ \\
\hline TSH-oma & 2 & $0.6 \%$ \\
\hline Total & 334 & \\
\hline Macroadenomas & 282 & $84.4 \%$ \\
\hline White people & 276 & $82.6 \%$ \\
\hline Male & 183 & $54.8 \%$ \\
\hline Average age (years) & 52.96 & \\
\hline
\end{tabular}

Abbreviation: TSH, thyroid-stimulating hormone.

significant, these conditions were still fairly uncommon in the non-CSF leak group-4\% had a history of CHF, 3\% had stroke, $4 \%$ had liver disease, and $4 \%$ had immunosuppression. Of the 14 comorbidities measured, none were significantly more common in the CSF leak group.

\section{Significant Differences in Clinical Complications}

There were also three postoperative clinical complications that occurred significantly less often in the CSF leak groupvenous thromboembolic event (VTE) $(p=0.014)$, decreased postoperative visual field ( $p=0.008$ ), and respiratory failure $(p=0.025)$-as shown in - Table 5. In the CSF leak group, none of the 13 patients had any of these complications. These complications were fairly uncommon in the nonleak group as well-2\% had VTE, $2 \%$ had decreased postoperative visual field, and $2 \%$ had respiratory failure. One postoperative clinical complications occurred significantly more often in the CSF leak group-DI $(\Delta=33.4 \%, p=0.040)$.

\section{Significant Differences in Surgical Outcomes}

Surgical outcomes had several notable differences (- Table 5). LOS after operation in the leak group was 5.08 days compared with 2.23 days in the nonleak group $(\Delta=2.84$ days, $p<0.001)$. Total LOS, which includes any additional days spent in the hospital on readmission, was 5.08 days in the leak group versus 2.79 days in the nonleak group $(\Delta=2.29$ days, $p<0.001)$. Reoperation rate was significantly higher in the CSF leak group (54 vs. $2 \%, p=0.004$ ). Thirty-day readmission rate was significantly less in the leak group $(\Delta=13 \%, p<0.001)$. Readmission LOS was less in the leak group $(\Delta=0.55$ days, $p<0.001)$. Postoperative ED visits were also fewer in the leak group $(\Delta=18 \%, p<0.001)$.

\section{Notable Nonsignificant Differences}

Contrary to some literature on CSF leak, there were no significant differences when comparing tumor characteristics (i.e., \% macroadenoma, nonsecreting type, and Cushing's disease). Acromegaly was the only condition approaching significance 
Table 5 Significant differences found between the CSF leak and nonleak groups: Categorized by preoperative variables, complications, and outcomes

\begin{tabular}{|c|c|c|c|c|c|}
\hline \multirow[t]{4}{*}{ Preop variables } & $\mathrm{H} / \mathrm{o} \mathrm{CHF}$ & $0.00 \%$ & $4.36 \%$ & $-4.36 \%$ & 0.000 \\
\hline & H/o stroke & $0.00 \%$ & $2.80 \%$ & $-2.80 \%$ & 0.003 \\
\hline & Liver disease & $0.00 \%$ & $4.36 \%$ & $-4.36 \%$ & 0.000 \\
\hline & Immune suppression & $0.00 \%$ & $3.74 \%$ & $-3.74 \%$ & 0.000 \\
\hline \multirow[t]{4}{*}{ Postoperative clinical complications } & Diabetes insipidus & $46.15 \%$ & $12.77 \%$ & $33.38 \%$ & 0.040 \\
\hline & DVT or PE & $0.00 \%$ & $1.87 \%$ & $-1.87 \%$ & 0.014 \\
\hline & Postoperative visual field change & $0.00 \%$ & $2.18 \%$ & $-2.18 \%$ & 0.008 \\
\hline & Respiratory failure & $0.00 \%$ & $1.56 \%$ & $-1.56 \%$ & 0.025 \\
\hline \multirow[t]{6}{*}{ Postoperative surgical outcomes } & LOS (days) & 5.08 & 2.23 & 2.84 & 0.000 \\
\hline & 30-day readmission & 0.00 & 0.13 & $-13.40 \%$ & 0.000 \\
\hline & Readmission LOS (days) & 0.00 & 0.55 & -0.55 & 0.000 \\
\hline & Total LOS (days) & 5.08 & 2.79 & 2.29 & 0.001 \\
\hline & 30-Day ED visits & $0.00 \%$ & $17.76 \%$ & $-17.76 \%$ & 0.000 \\
\hline & 30-Day Reoperation & $53.85 \%$ & $2.18 \%$ & $51.67 \%$ & 0.004 \\
\hline
\end{tabular}

Abbreviations: CHF, chronic heart failure; ED, emergency department; DVT, deep vein thrombosis; LOS, length of stay; PE, pulmonary embolism.

(7.7\% in leak group vs. $23.7 \%$ in nonleak group, $p=0.07$ ). In addition, unlike some of the studies mentioned in the introduction, demographic data was not significantly different, including age at operation, \% of male, \% of white race, and BMI (-Table 6). Notably, in our patient population, the average $\mathrm{BMI}$ is in the "obese" range for both leak and nonleak patients.

\section{Preoperative Variables that Predict CSF Leak Complication in Multivariate Analysis}

Multivariate binary logistic regression demonstrated that of the various types of tumors studied, none were significantly

Table 6 Notable nonsignificant differences in tumor characteristics and patient demographics

\begin{tabular}{|l|l|l|l|l|}
\hline & $\begin{array}{l}\text { CSF } \\
\text { leak }\end{array}$ & $\begin{array}{l}\text { Non-CSF } \\
\text { leak }\end{array}$ & Difference & $p$ Value \\
\hline Nonsecreting & $53.8 \%$ & $60.1 \%$ & $-6.3 \%$ & 0.68 \\
\hline Secreting & $46.2 \%$ & $39.9 \%$ & $6.3 \%$ & 0.68 \\
\hline Acromegaly & $7.7 \%$ & $23.7 \%$ & $-16.0 \%$ & 0.07 \\
\hline $\begin{array}{l}\text { Cushing's } \\
\text { disease }\end{array}$ & $15.4 \%$ & $11.8 \%$ & $3.5 \%$ & 0.74 \\
\hline Prolactinoma & $15.4 \%$ & $3.7 \%$ & $11.6 \%$ & 0.29 \\
\hline TSH-oma & $0.00 \%$ & $0.62 \%$ & $-0.6 \%$ & 0.16 \\
\hline Macroadenomas & $92.3 \%$ & $84.1 \%$ & $8.2 \%$ & 0.32 \\
\hline White race & $92.3 \%$ & $82.2 \%$ & $10.1 \%$ & 0.23 \\
\hline Male & $61.5 \%$ & $54.5 \%$ & $7.0 \%$ & 0.63 \\
\hline $\begin{array}{l}\text { Average age } \\
\text { (years) }\end{array}$ & 56.5 & 52.8 & 3.7 & 0.44 \\
\hline BMI & 34.66 & 32.50 & 2.16 & 0.44 \\
\hline
\end{tabular}

Abbreviations: BMI, body mass index; CSF, cerebrospinal fluid; TSH, thyroid-stimulating hormone. associated with CSF leak, although prolactinomas approached significance (odds ratio [OR], 6.35; 95\% confidence interval $[C I], 0.71-40.45 ; p=0.062)$. Of the comorbidities studied, only patients with a history of radiation to the skull base were found to have an association with CSF leak (OR, 8.67; 95\% CI, $0.94-$ $57.03 ; p=0.031$ ). Importantly, both of these variables had CIs that included the null hypothesis.

\section{Postoperative Outcomes Variables Associated with CSF Leak in Multivariate Analysis}

Multivariate binary logistic regression showed that patients with postoperative intracranial infection had 28.73 times greater odds of also having postoperative CSF leak (OR, 28.73; $95 \% \mathrm{CI}, 2.04-438.7 ; p=0.012$ ). Interestingly, the presence of CSF leak did not affect LOS (OR, 1.00; 95\% CI, 1.09-1.67; $p=0.005$ ). Notably, both postoperative intracranial infection and LOS had Cls that did not include the null hypothesis. In addition, patients with postoperative intracerebral hemorrhage had 17.44 greater odds of also having CSF leak (OR, 17.44; 0.65$275.3 ; p=0.044)$, although the $\mathrm{Cl}$ of this relationship included the null hypothesis. While patients with postoperative DI had 11.02 increased odds of also having postoperative CSF leak, this finding only approached significance (OR, 11.02 ; $95 \% \mathrm{CI}, 0.45$ $102.7 ; p=0.064)$. ORs and Cls for variables with $p<0.9$ in multivariate analysis are displayed ( $\sim$ Table 7 ).

\section{Financial Consequences of CSF Leak}

Average hospital costs for patients with CSF leak compared with those without CSF leak were $\$ 33,684$ and 18,041 , respectively $(p<0.05)$. Average hospital charges for patients with CSF leak compared with those without CSF leak were $\$ 99,281$ and 53,255 , respectively $(p<0.05)$. Average hospital payments for patients with CSF leak compared with those without CSF leak were $\$ 30,467$ and 22,868 , respectively, but this difference was 
Table 7 Univariate and multivariate logistic regression models of variables associated with CSF leak

\begin{tabular}{|c|c|c|c|c|c|c|c|c|}
\hline & & & \multicolumn{3}{|c|}{ Univariate analysis } & \multicolumn{3}{|c|}{ Multivariate analysis } \\
\hline & & & $p$-Value & $\begin{array}{l}\text { Odds } \\
\text { ratio }\end{array}$ & $\begin{array}{l}95 \% \text { Confidence } \\
\text { interval }\end{array}$ & $p$-Value & $\begin{array}{l}\text { Odds } \\
\text { ratio }\end{array}$ & $\begin{array}{l}95 \% \text { Confidence } \\
\text { interval }\end{array}$ \\
\hline \multirow{7}{*}{$\begin{array}{l}\text { Operative } \\
\text { data }\end{array}$} & \multirow[t]{6}{*}{ Tumor type } & Macroadenoma & 0.443 & & & & & \\
\hline & & Acromegaly & 0.214 & & & & & \\
\hline & & Cushing's disease & 0.691 & & & & & \\
\hline & & TSH-oma & 0.994 & & & & & \\
\hline & & Prolactinoma & 0.061 & & & 0.062 & 6.35 & $0.71-40.45$ \\
\hline & & Nonsecreting & 0.632 & & & & & \\
\hline & \multicolumn{2}{|l|}{ LOS (days) } & 0.0003 & 1.36 & $1.16-1.60$ & 0.005 & 1.00 & $1.09-1.67$ \\
\hline \multirow[t]{3}{*}{ Demographics } & \multicolumn{2}{|c|}{ Age at surgery } & 0.415 & & & & & \\
\hline & \multicolumn{2}{|l|}{ Male gender } & 0.609 & & & & & \\
\hline & \multicolumn{2}{|l|}{ White race } & 0.360 & & & & & \\
\hline \multirow{14}{*}{$\begin{array}{l}\text { Preoperative } \\
\text { variables }\end{array}$} & \multicolumn{2}{|l|}{ History of MI } & 0.703 & & & & & \\
\hline & \multicolumn{2}{|c|}{ History of CHF } & 0.993 & & & & & \\
\hline & \multicolumn{2}{|c|}{ History of stroke } & 0.991 & & & & & \\
\hline & \multicolumn{2}{|c|}{ Preop visual field cut } & 0.538 & & & & & \\
\hline & \multicolumn{2}{|c|}{ Preop visual acuity } & 0.510 & & & & & \\
\hline & \multicolumn{2}{|c|}{ History of pulmonary disease } & 0.659 & & & & & \\
\hline & \multicolumn{2}{|c|}{ Diabetes mellitus } & 0.813 & & & & & \\
\hline & \multicolumn{2}{|l|}{ Renal disease } & 0.143 & & & 0.462 & 3.06 & $0.08-39.25$ \\
\hline & \multicolumn{2}{|l|}{ Liver disease } & 0.993 & & & & & \\
\hline & \multicolumn{2}{|c|}{ Blood thinners } & 0.911 & & & & & \\
\hline & \multicolumn{2}{|c|}{ History of radiation to skull base } & 0.048 & 5.12 & $0.74-22.20$ & 0.031 & 8.67 & $0.94-57.03$ \\
\hline & \multicolumn{2}{|c|}{ History of prior pituitary surgery } & 0.526 & & & & & \\
\hline & Immunosupp & ssion & 0.900 & & & & & \\
\hline & BMI & & 0.335 & & & & & \\
\hline Postoperative & Diabetes insi & & 0.002 & 5.87 & $1.81-18.47$ & 0.064 & 11.02 & $0.45-102.7$ \\
\hline complications & Desmopressi & equired & 0.004 & 5.64 & $1.62-17.99$ & 0.702 & 0.61 & $0.06-14.59$ \\
\hline & Intracerebral & morrhage & 0.040 & 13.29 & $0.59-148.4$ & 0.044 & 17.44 & $0.65-275.3$ \\
\hline & Symptomatic & neumocephalus & 0.990 & & & & & \\
\hline & Intracranial i & ction & 0.001 & 29.08 & $3.24-259.8$ & 0.012 & 28.73 & $2.04-438.7$ \\
\hline & Cranial nerve & jury & 0.993 & & & & & \\
\hline & DVT or PE & & 0.993 & & & & & \\
\hline & Severe arrhy & & 0.426 & & & & & \\
\hline & Hyponatrem & & 0.053 & & & 0.088 & 3.54 & $0.79-15.01$ \\
\hline & Hypernatrem & & 0.151 & & & 0.496 & 0.52 & $0.07-3.17$ \\
\hline & Postoperativ & isual field change & 0.992 & & & & & \\
\hline & Postoperativ & isual acuity change & 0.569 & & & & & \\
\hline & Respiratory $f$ & & 0.990 & & & & & \\
\hline Postoperative & 30-Day readr & sion & 0.992 & & & & & \\
\hline $\begin{array}{l}\text { surgical } \\
\text { outcomes }\end{array}$ & Readmission & & 0.992 & & & & & \\
\hline & Total LOS & & 0.017 & 1.15 & $0.997-1.24$ & 0.149 & 1.13 & $0.94-1.32$ \\
\hline & 30-Day ED vi & & 0.991 & & & & & \\
\hline & 30-Day reope & tion & 0.992 & & & & & \\
\hline & 30-Day mort & & 0.992 & & & & & \\
\hline
\end{tabular}

Abbreviations: BMI, body mass index; CHF, chronic heart failure; CSF, cerebrospinal fluid; DVT, deep vein thrombosis; ED, emergency department; LOS, length of stay; MI, myocardial infarction; PE, pulmonary embolism; TSH, thyroid-stimulating hormone. 
Predictive Factors, 30-Day Clinical Outcomes, and Costs Associated with CSF Leak in Pituitary Adenoma

Table 8 Hospital charges, costs, and payments for cases with CSF leak

\begin{tabular}{|l|l|l|l|}
\hline Financial metrics (\$) & CSF leak group $(\boldsymbol{n}=13)$ & Non-CSF leak group $(\boldsymbol{n}=\mathbf{3 2 2})$ & $\boldsymbol{p}$-Value \\
\hline Average total hospital charges & 99,281 & 53,255 & $<0.05$ \\
\hline Average total hospital costs & 33,684 & 18,041 & $<0.05$ \\
\hline Average total hospital payments & 30,467 & 22,868 & 0.14 \\
\hline Average net hospital profit (payment-cost) & $-3,217$ (loss) & 4,385 (gain) & 0.06 \\
\hline
\end{tabular}

Abbreviation: CSF, cerebrospinal fluid.

not significant $(p=0.14)$. The average net profit (payment minus cost) from patient cases with CSF leak compared with those without CSF leak was- $\$ 3,217$ (loss) and 4,385 (gain), respectively, which approached significance $(p=0.06)$. Average hospital costs, charges, and payments for CSF leak and nonleak patients are shown in - Table 8 .

When identifying cost drivers and variability in cost by category, the average percentage of contribution of a particular financial subcategory (e.g., pharmacy, magnetic resonance imaging/magnetic resonance angiography [MRI/ MRA], and supplies/implants) to a cost metric was calculated and plotted (-Fig. 1). Those subcategories for which less than $2 \%$ of either hospital charges, costs, or payments was attributed were not plotted but are listed in - Table 9 .

For hospital charges, OR time (23.12 $\pm 5.35 \%)$, supplies/ implants (e.g., absorbable packing or tissue glue) $(18.78 \pm 4.43 \%)$, and room and board (15.78 $\pm 5.62 \%)$ were the top contributors in order (-Fig. 1). In contrast, room and board constituted the highest percentage of hospital total costs ( $27.60 \pm 10.02 \%)$, followed by time-based OR $(21.99 \pm 6.10 \%)$ and supplies/implants (19.42 $\pm 7.13 \%)$. For hospital payments, time-based OR, supplies/implants, and room and board were the primary contributors in order, with the same percentages as for hospital charges (-Fig. 1). Notably, room and board are the largest hospital cost driver yet only the third highest factor in both hospital charge and hospital payment.

Hospital direct variable costs, a component of total costs, were primarily driven by supplies/implants (26.78 $\pm 10.63 \%)$, room and board $(23.37 \pm 8.86 \%)$, and time-based OR (22.32 $\pm 7.96 \%)$. Professional charges, a component of total hospital charges, were also examined by a different set of subcategories (less than those listed in -Fig. 1). These data are plotted in - Fig. 2. The primary driver for professional charges was surgical procedures $(77.69 \pm 5.10 \%)$. Among the other subcategories, anesthesia was the only one that represented greater than $10 \%$ of average professional charges $(11.00 \pm 3.77 \%)$.

We next compared the various modalities of CSF leak intervention-lumbar drain, surgery alone, or a combination of both-for average total hospital costs, average total hospital charges, average professional charges, average total hospital payments, average profit, and average LOS. As shown in -Table 10, average total hospital costs for lumbar drain $(n=6)$, surgery alone $(n=4)$, and combination $(n=3)$ were $\$ 26,353,31,285$, and 51,547, respectively. Average hospital

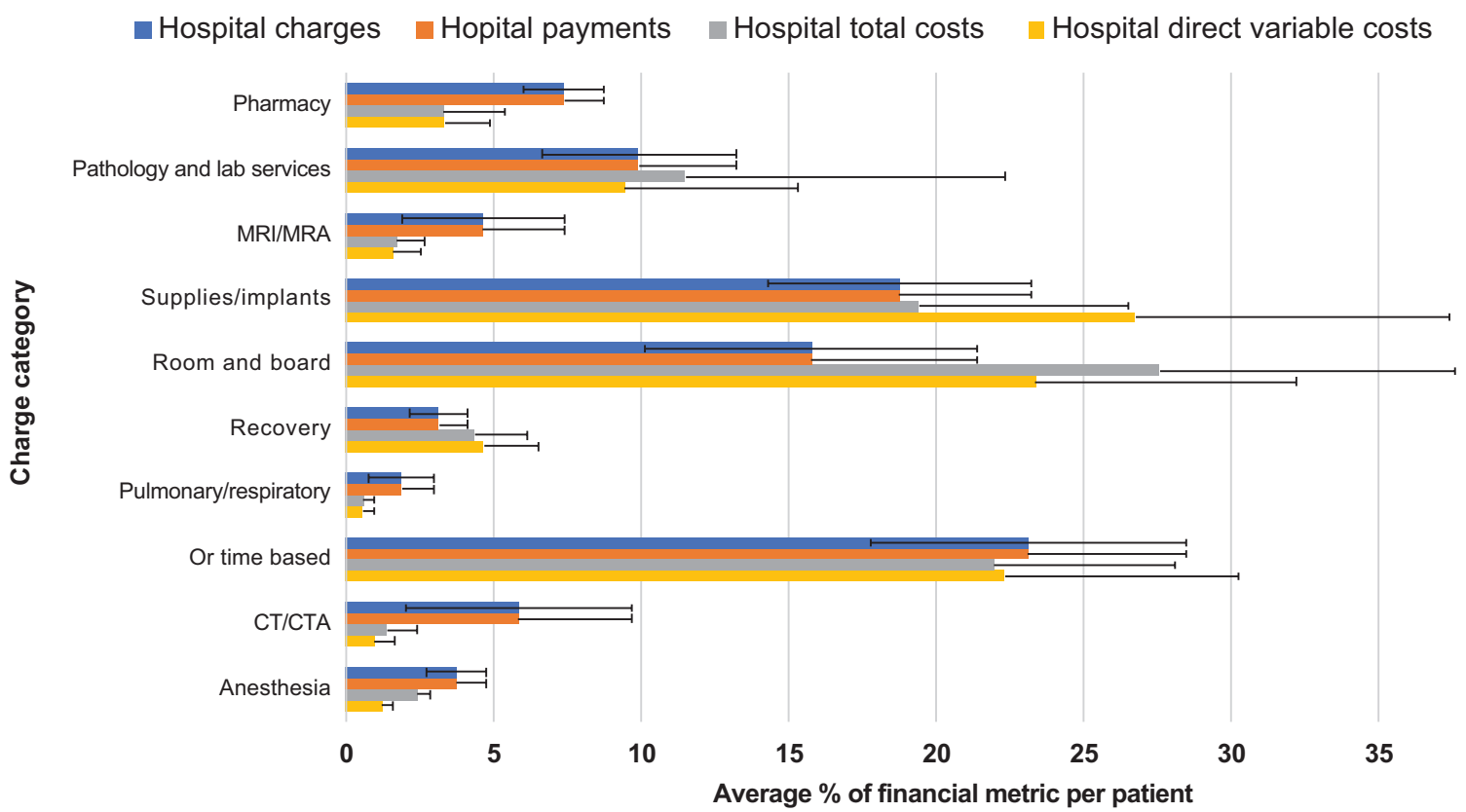

40

Fig. 1 Average hospital charges, payments, and costs for cases with a cerebrospinal fluid leak complication, broken down by financial subcategory. Abbreviations: CT, computed tomography; CTA, computed tomography angiography; MRI, magnetic resonance imaging; MRA, magnetic resonance angiography. 
Table 9 Financial subcategories with $<2 \%$ financial contribution to hospital charges, payments, and costs

\begin{tabular}{|l|}
\hline Financial subcategories \\
\hline Drug admin \\
\hline Hospital outpatient department \\
\hline Blood/transfusion \\
\hline Cardiac services \\
\hline EEG \\
\hline Emergency services \\
\hline EKG \\
\hline Peripheral vascular laboratories \\
\hline Physical therapy/occupational therapy/speech \\
\hline Reference laboratories \\
\hline Market priced services \\
\hline Neurology \\
\hline Nuclear medicine/PET \\
\hline Ophthalmologic evaluation services \\
\hline Ultrasound \\
\hline X-ray \\
\hline
\end{tabular}

Abbreviations: EEG, electroencephalogram; EKG, electrocardiogram; $\mathrm{PT} / \mathrm{OT}$, physical therapy/occupational therapy; PET, positron emission tomography.

charges for lumbar drain, surgery alone, and combination were $\$ 84,610,84,648$, and 148,144 , respectively. Average professional charges for lumbar drain, surgery alone, and combination were $\$ 35,556,37,729$, and 42,333 , respectively. Average total hospital payments for lumbar drain, surgery alone, and combination were $\$ 19,056,40,897$, and 39,385 , respectively. Average profit for lumbar drain, surgery alone, and combination was -\$7,927 (loss), 9,612 (gain), and 12,162 (loss), respectively. Finally, average LOS (in days) for patients treated with lumbar drain, surgery alone, and combination were $6.3 \pm 1.4,3.8 \pm 1.0$, and $4.3 \pm 2.1$, respectively. A comparison of differences among lumbar drain, surgery alone, and combination treatment revealed a significant difference only between lumbar drain and surgically treated patients in regard to average total hospital payments, average profit, and average LOS.

\section{Discussion}

CSF leak is one of the most common complications following pituitary adenoma resection. ${ }^{4-6}$ Although its prevalence is well understood, research into its risk factors, clinical implications, and costs is limited. Surgeons operating on patients with pituitary adenomas can potentially change their clinical management to decrease the frequency of CSF leak and reduce costs. Our study, to date, examines the largest set of clinical correlates and financial drivers of CSF leak in patients that have undergone pituitary adenoma resection.

It is worth discussing our standard procedures in this group. This analysis is for patients operated on by a single team of surgeons over a 5-year time course which was during rapid expansion of the program and was fairly early in our team's learning curve. Now, we perform well over 100 pituitary operations annually as a single team, and standardization of processes has increased over time. During the time period of study, the operations and postoperative care always included intraoperative image-guidance, frequently included fat graft reconstruction with or without pedicled flap, routinely included early inpatient postoperative MRI to evaluate completeness of resection, and routinely included postoperative

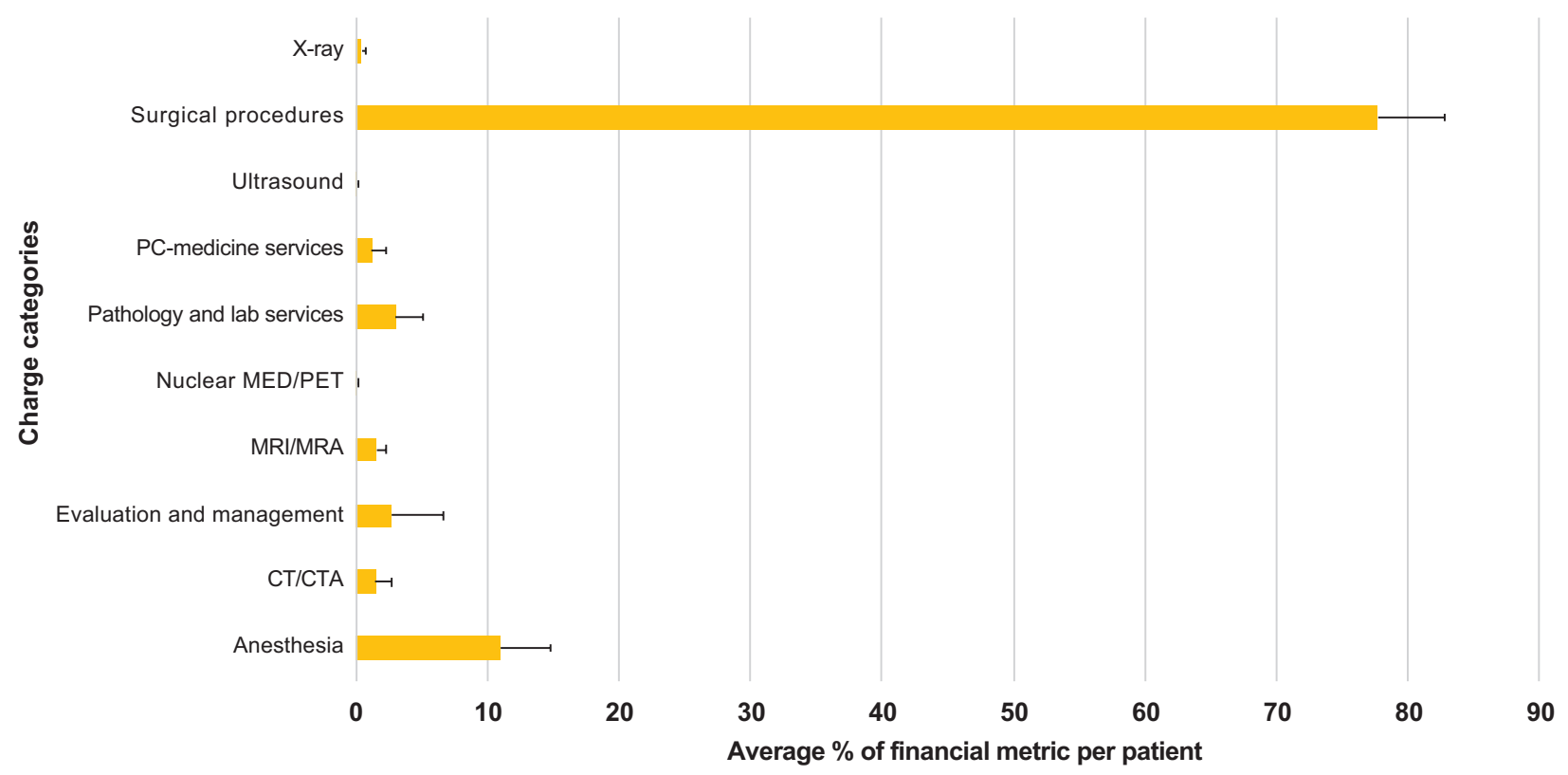

Fig. 2 Professional charges for cases with a cerebrospinal fluid leak complication, broken down by financial subcategory. Surgical procedures are highest contributor to professional charges. Abbreviations: CT, computed tomography; CTA, computed tomography angiography; MRI, magnetic resonance imaging; MRA, magnetic resonance angiography. 
Predictive Factors, 30-Day Clinical Outcomes, and Costs Associated with CSF Leak in Pituitary Adenoma

Table 10 Hospital charges, total costs, professional charges and LOS among CSF leak interventions

\begin{tabular}{|c|c|c|c|c|c|c|}
\hline \multirow[t]{2}{*}{ Financial metrics (\$) } & \multirow{2}{*}{$\begin{array}{l}\text { Lumbar } \\
\text { drain } \\
(n=6)\end{array}$} & \multirow{2}{*}{$\begin{array}{l}\text { Surgery } \\
\text { alone } \\
(n=4)\end{array}$} & \multirow{2}{*}{$\begin{array}{l}\text { Surgery and } \\
\text { lumbar drain } \\
(n=3)\end{array}$} & \multicolumn{3}{|l|}{$p$-Values } \\
\hline & & & & $\begin{array}{l}\text { Drain versus } \\
\text { surgery alone }\end{array}$ & $\begin{array}{l}\text { Drain versus } \\
\text { both }\end{array}$ & $\begin{array}{l}\text { Surgery alone } \\
\text { versus both }\end{array}$ \\
\hline Average total hospital charges & 84,610 & 84,648 & 148,133 & 1.0 & 0.5 & 0.5 \\
\hline Average professional charges & 35,556 & 37,729 & 42,333 & 0.6 & 0.4 & 0.7 \\
\hline Average total hospital costs & 26,353 & 31,285 & 51,547 & 0.3 & 0.4 & 0.5 \\
\hline Average total hospital payments & 19,056 & 40,897 & 39,385 & $<0.05$ & 0.4 & 0.9 \\
\hline $\begin{array}{l}\text { Average total hospital profit } \\
\text { (payment-cost) }\end{array}$ & $-7,297$ & 9,612 & $-12,162$ & $<0.05$ & 0.3 & 0.9 \\
\hline Average LOS (days) & $6.3 \pm 1.4$ & $3.8 \pm 1.0$ & $4.3 \pm 2.1$ & $<0.01$ & 0.2 & 0.7 \\
\hline
\end{tabular}

Abbreviations: CSF, cerebrospinal fluid; LOS, length of stay.

staged endoscopic sinonasal debridement. Patients were sent to a neurosurgical care floor directly, with no intensive care unit stay. In more recent years, volume has increased, operative time has decreased, and the approach has become less invasive. It will be important for us to examine changes to patient outcomes and financial implications based on changes to standard processes over time.

The incidence of CSF leak in our study population of 3.9\% was comparable to previous studies examining CSF leak following transsphenoidal surgery. ${ }^{7,19}$ of the 20 preoperative variables studied between groups (CSF leak vs. nonleak), none were significantly more common in the CSF leak group (-Table 1). This is in contrast to some previous studies. Ivan et al found that nonideal BMI was associated with postoperative CSF leak in a cohort of 98 consecutive patients operated on at the University of California, San Francisco (11 patients had CSF leaks). ${ }^{12}$ It is important to recognize that in this study, a statistical significance was only found when these patients were grouped as either abnormal BMI $(<18.5$ or $\left.>25 \mathrm{~kg} / \mathrm{m}^{2}\right)$ or normal BMI $\left(18.5-25 \mathrm{~kg} / \mathrm{m}^{2}\right)$. BMI itself was not an independent risk factor. In a study in Singapore, where obesity benchmarks are set at lower BMIs, BMI was found to be an independent risk factor for CSF leak: $27.0 \mathrm{~kg} / \mathrm{m}^{2}$ versus $24.6 \mathrm{~kg} / \mathrm{m}^{2} ; p=0.018 .^{20}$ There were three other studies that noted a correlation between BMI and CSF leak, ${ }^{11,13,14}$ although Lobatto et al conducted a systematic review and rated these studies with moderate-to-high bias. ${ }^{9}$ In our study, there was no significant difference between the groups. BMI in leak versus nonleak group was 32.62 versus $32.54, p=0.97$. In addition, multivariate analysis did not suggest an association between BMI and CSF leak. Potential confounders include demographic differences between the patient populations in these studies. For example, in the state of Michigan, where most our patients are from, the obesity rate was $31.6 \%$ in $2016 .{ }^{21}$ In California (where most of Ivan et al's cohort is likely from), the obesity rate was only $25.0 \%$.

Similarly to the between-groups analysis that did not reveal significantly more common preoperative variables in the CSF leak group, multivariate analysis did not find significant contributions of these same variables to CSF leak. However, the association of prolactinomas with CSF approached significance (OR, 6.35; 95\% CI, 0.71-40.45; $p=0.062$ ). The association between prolactinoma and postoperative CSF leak has not been clearly demonstrated before. In one literature review on spontaneous and medically induced CSF, the authors noted larger and invasive adenomas cause tumor expansion into surrounding dural structures, and some functional adenomas, such as growth hormone-secreting adenomas and prolactinomas, frequently invade sellar and infrasellar spaces. Nonfunctioning macroadenomas, meanwhile, have a tendency to invade the suprasellar space. In cases with additional invasion of the arachnoid and/or brain parenchyma, there is greater risk for development of a CSF fistula. As long as the tumor is large enough to occlude the opening, thereby "plugging" this opening, the escape of CSF can be prevented. However, reduction in tumor size, either due to medical or surgical therapy, can inadvertently lead to CSF escape. ${ }^{22}$ Nevertheless, a larger cohort study, especially one aimed at specifically investigating the effect of tumor type on postoperative CSF leak, will help elucidate further whether prolactinoma is an independent factor for postoperative CSF leak.

In regard to prior treatment, Nishioka et al found that previous transsphenoidal surgery and skull base radiation were each independent risk factors for postoperative CSF rhinorrhea. ${ }^{10}$ The rate of prior transsphenoidal surgery in our population was 23 versus $16 \%(p=0.59)$ in the leak and nonleak group, respectively. History of prior radiation to the skull base in our patients was 15 versus $3 \%(p=0.28)$ in the leak versus nonleak group, respectively. Although the difference is large, it did not reach significance in between-groups comparison. However, in multivariate analysis, previous skull base radiation was associated with greater odds of postoperative CSF leak, thereby supporting the findings in literature (OR, 8.67; 95\% CI, 0.94-57.03; $p=0.031)$. Again, the $\mathrm{Cl}$ included the null hypothesis. A larger cohort study is necessary to adequately delineate the significance of prior skull base radiation in future postoperative CSF leak complications.

DI was found to be significantly higher in the CSF group in between-group comparisons $(\Delta=34 \%, p=0.04)$. Conceptually, the increased frequency of DI in the leak group makes sense. A more aggressive surgical approach to resect pituitary tumor can affect the posterior pituitary, ultimately suppressing antidiuretic hormone secretion and leading to DI. However, in multivariate analysis, the association of CSF 
leak and DI only approached significance (OR, $11.02 ; 95 \% \mathrm{CI}$, 0.45-102.7; $p=0.064$ ).

For certain comorbidities, the prevalence within this population was too low to find significant association with CSF leak. We found that several comorbidities were actually associated with a decreased risk of CSF leak-history of CHF, stroke, liver disease, and immunosuppression. In fact, of the 13 patients that had CSF leak, none of them had any of these four comorbidities. To our knowledge, these variables' effects on CSF leak likelihood have not been specifically studied. Physiologically, we do not believe that any of these four conditions are related to CSF leak. Rather, we believe, again, that the significant differences between the leak and nonleak group are due to our cohort not being large enough to capture these rare comorbidities. To illustrate this, let us consider history of stroke, which was very rare in the nonleak group at $3 \%$. If we assume that this rate is the same in the leak group of 13 patients, we expect less than one patient to have a history of stroke ( $3 \%$ x 13 patients $=0.6$ patients). Not surprisingly, we have zero patients with a history of stroke in the leak group. Similarly, the rate of CHF, liver disease, and immunosuppression were all below $4.4 \%$ in the nonleak group and none were present in our 13 patients that had CSF leak. For this reason, we doubt that these variables are actually protective against CSF leak, despite the strong statistical significances shown in - Table 5. As discussed previously, multivariate analysis showed that only history of radiation to the skull base had a $p$-value less than 0.5 out of all the preoperative variables, although the $\mathrm{Cl}$ included the null hypothesis. We recommend that future studies examine larger cohorts to better identify if these variables, particularly history of radiation to the skull, are truly different in leak and nonleak patients.

There were three postoperative complications that appeared to be less common in the CSF leak group-VTE, decreased postoperative visual field, and respiratory failure. Again, we noticed that of the 13 patients with CSF leak, none of them had any of these three complications. A similar phenomenon explained in the paragraph above likely explains these findings, as well. All three of these complications were very rare in the nonleak group; the rates were all under 3\%. Because of these very low rates in the nonleak, it should not be surprising that we do not see any of these complications in the CSF leak group despite the significant $p$-values when comparing the two groups.

Multivariate analysis, on the other hand, identified two significant postoperative complications-intracranial infection and intracerebral hemorrhage. Postoperative intracranial infection was found to have 28.73 times greater odds of also having postoperative CSF leak (OR, 28.73; 95\% CI, 2.04-438.7; $p=0.012$ ). It is known that CSF leak increases the risk of meningitis after skull base surgery, with one study demonstrating a relative risk of $14.6 .^{23}$ One explanation for this association may be attributed to lumbar drainage-related infection. Of note, the rate of intracranial infections in our CSF leak population was 15 versus $1 \%$ in the nonleak group, but between-groups analysis revealed a nonsignificant difference $(p=0.18)$. Given the small sample size and that 9 out of the 13 (69\%) CSF leak patients had lumbar drainage, it is difficult to compare the effect of lumbar drainage on the rate of intracranial infections in our population. Nevertheless, our analysis shows that the odds of developing intracranial infection are higher in CSF leak patients. These findings shed light on existing unanswered questions regarding management of CSF leak, such as whether patients with CSF leak should be treated with broad-spectrum antibiotics and whether surgeons should consider surgical repair over lumbar drain to treat CSF leak and prevent infection.

In between group comparisons, the CSF leak group had 8\% postoperative intracerebral hemorrhage compared with $1 \%$ in the nonleak group, which was not significant $(p=0.38)$. However, in multivariate analysis, intracerebral hemorrhage was found to be significantly associated with CSF leak, although the $\mathrm{CI}$ included the null hypothesis (OR, 17.44; $95 \% \mathrm{CI}, 0.65-275.3 ; p=0.044)$. From our literature review, there is no study specifically comparing the association of hemorrhage with CSF leak. However, Lobatto et al's systematic review highlights the major risk factors for bleeding in transsphenoidal resection of pituitary adenomas-most notably internal carotid artery (ICA) injury. Risk factors for ICA injury are prior radiation and intraventricular extension. ${ }^{9,13}$ Interestingly, these variables have also been found to be risk factors for CSF leak. ${ }^{9,13,14}$ With these risk factors in mind, it would not be surprising to have a patient with both CSF leak and intracerebral hemorrhage.

Regarding the LOS, as expected, the CSF leak group had an average hospital stay after surgery that was 2.8 days longer. As shown in - Table 7, univariate analysis also suggested this association (OR, 1.36; 95\% CI, 1.16-1.60; $p<0.001)$. However, in multivariate analysis, the OR decreased to 1.0 (OR, 1.00 ; $95 \% \mathrm{CI}, 1.09-1.67 ; p=0.005$ ), suggesting that the influence of CSF leak itself on LOS becomes less influential in the context of the additional variables studied here.

Readmission rates were also significantly less in leak patients ( 0 vs. $13 \%, p<0.001$ ), but this variable was not significantly associated with CSF leak in univariate analysis. It is possible that there are fewer readmissions in the leak group since they receive additional monitoring due to their longer initial hospital stay. Nonetheless, almost all postoperative leaks are found early, prior to discharge, thus not requiring readmission. Reoperation rate was unsurprisingly found to be significantly higher in the CSF leak group (54 vs. $2 \%, p=0.004$ ) in between-groups comparison, but this was not a significant variable in univariate analysis. Nevertheless, in our cohort, CSF leak was the most common reason for reoperation. We occasionally reoperate for residual functional adenoma and postoperative epistaxis

In the process of understanding and managing postoperative CSF leaks, it is important to consider not only the comorbidities, surgical complications, and clinical outcomes but also the financial consequences. Previous studies have noted that CSF leak patients had higher costs, primarily due to OR time and room \& board- findings that are interesting but also not very surprising to most surgeons. The literature currently lacks depth to properly analyze the more stratified cost drivers and delves very little into charges and payments. Without these more granular analyses, it is difficult for a 
hospital to identify an area of their practice to address to decrease costs and increase financial value.

It is worth briefly considering cost accounting. As noted in the methods section, financial data collected on our cohort included total hospital costs (what it costs internally to provide the care, allocated directly and indirectly), charges (the price tag to the payor/patient for hospital and professional services), and payments (what the hospital is actually paid for the care provided) for the hospital billing encounters associated with the pituitary operations. Charges and payments are relatively straightforward, but cost has many challenges in its assessment. Costs are assigned by the health system directly (patient-specific) or indirectly ("overhead"). Direct costs may be variable (e.g., the cost for an implant used for the specific patient; this is variable in its use and only charged when used, so the cost is essentially "all or none") or fixed (e.g., the cost to provide nursing care to the patient on a specific unit for the day or session; the hospital will pay the entire day's salary no matter how much nursing time is actually spent). Indirect costs comprise the costs to "keep the lights on," and these are generally allocated evenly across patients or units. We have not evaluated here how these costs are specifically assigned by the health system and have only recorded the costs as provided to us.

We found that average total hospital costs and hospital charges for patients with CSF leak were significantly higher than those for patients without this complication, and hospital costs for CSF leak cases were primarily driven by room and board charges. While CSF leak resulted in increased hospital payments, the net profit (payment minus cost) from cases with CSF leak was a loss, compared with a gain in profit from those without CSF leak (-Table 8). One study examining cost of postoperative CSF leak across multiple neurosurgical procedures found that, on average, procedures involving a CSF leak cost $141 \%$ more than those that did not result in postoperative CSF leak. ${ }^{8}$ Another study examining costs associated with CSF leak in cerebellopontine angle surgery found that the median cost of a CSF leak was $\$ 50,401 .^{24}$ Our data did not show as large of a difference between the two groups; however, the cost of leak was still 87\% higher than the nonleak group.

The high cost of a CSF leak complication may be, in part, explained by associations with other complications and subsequent management. We found that postoperative intracranial infection, for example, was significantly associated with CSF leak, and indeed this is corroborated in literature. ${ }^{23}$ Downstream complications past 30-days in the postoperative period were not followed in the present study. We suggest examining larger cohorts of patients in a longer postoperative window to better study the relationships of CSF leak with associated clinical complications and subsequent costs.

Examining financial drivers yielded primary contributions to total hospital charges, total hospital costs, hospital payments, and hospital direct variable costs by supplies/ implants, room and board, and time-based OR subcategories. More generally, these subcategories can be attributed to surgery and hospital stay. Not surprisingly, as evidenced by the longer LOS for patients with CSF leak, room and board were a primary cost driver. Interestingly, however, room and board charges were only the third largest contributor to hospital charges and payments, with time-based OR and supplies/implants as the first and second largest contributors, respectively, to both categories. Therefore, measures to decrease patient LOS, understandably, would reduce hospital costs and improve profits.

Our hypothesis in terms of management of CSF leaks was that early surgical intervention would actually be less costly overall than management with a lumbar drain, assuming that early surgical intervention would decrease LOS relative to prolonged lumbar drainage. Indeed, we found that surgical management of CSF leak decreases average LOS but raises hospital costs, although the latter difference was not significant (-Table 10). Surgery also increases hospital payments, with a positive net profit compared with lumbar drain alone (profit of $\$ 9,612$ vs. -7,927, $p<0.05)$. The method of treatment for postoperative CSF leak-lumbar drain versus surgery versus combination-was not significantly different in hospital charges, professional charges, or costs. However, surgical management of postoperative CSF leak required a shorter admission and received higher payments than lumbar drain, thus leading to a more favorable financial outcome for the hospital. If a patient can be clinically managed effectively with either surgery or lumbar drain, it may be prudent to opt for the surgical option.

Surgical decision-making during an operation, which can be dependent on factors such as surgeon experience, specialty training (neurosurgery vs. otolaryngology), and extensiveness of the operation, may have implications on the probability of CSF leak and ensuing financial burdens. When it comes to surgeon experience, more extensive experience with transsphenoidal surgery, defined by more than 500 previous operations, has been found, understandably, to be associated with a decreased percentage of postoperative complications, including CSF leak. ${ }^{19}$ As a result, we hypothesize that more advanced training and experience leads to lower costs associated with CSF leak. More research needs to be done to specifically explore this topic, and we will continue to follow our own outcomes over time.

Albeit retrospective, this study has, importantly, delineated cost drivers associated with CSF leak in transsphenoidal surgery for pituitary tumors. Previous studies have either focused on specific neurosurgical procedures or examined financial metrics without deconstructing the subcategories for which costs are attributed. Our study is limited as it was conducted in a single-center retrospective method. However, these data illuminate the importance of reducing LOS and conserving both time and resources in surgery without compromising treatment as they relate to economic savings for CSF leak. Financial considerations must be balanced with optimal clinical outcomes.

\section{Conflict of Interest}

None. 


\section{References}

1 Dehdashti AR, Ganna A, Karabatsou K, Gentili F. Pure endoscopic endonasal approach for pituitary adenomas: early surgical results in 200 patients and comparison with previous microsurgical series. Neurosurgery 2008;62(05):1006-1015, discussion 1015-1017

2 Gondim JA, Schops M, de Almeida JP, et al. Endoscopic endonasal transsphenoidal surgery: surgical results of 228 pituitary adenomas treated in a pituitary center. Pituitary 2010;13(01):68-77

3 Zada G, Kelly DF, Cohan P, Wang C, Swerdloff R. Endonasal transsphenoidal approach for pituitary adenomas and other sellar lesions: an assessment of efficacy, safety, and patient impressions. J Neurosurg 2003;98(02):350-358

4 Amano K, Hori T, Kawamata T, Okada Y. Repair and prevention of cerebrospinal fluid leakage in transsphenoidal surgery: a sphenoid sinus mucosa technique. Neurosurg Rev 2016;39(01):123-131, discussion 131

5 Berker M, Hazer DB, Yücel T, et al. Complications of endoscopic surgery of the pituitary adenomas: analysis of 570 patients and review of the literature. Pituitary 2012;15(03):288-300

6 Cappabianca P, Cavallo LM, Colao A, de Divitiis E. Surgical complications associated with the endoscopic endonasal transsphenoidal approach for pituitary adenomas. J Neurosurg 2002;97 (02):293-298

7 Piek J, Weber C, Kundt G, et al. Pharmacoeconomical consequences of postoperative CSF leaks after intracranial surgery - a prospective analysis. J Neurol Surg A Cent Eur Neurosurg 2012;73 (01):25-28

8 Grotenhuis JA. Costs of postoperative cerebrospinal fluid leakage: 1-year, retrospective analysis of 412 consecutive nontrauma cases. Surg Neurol 2005;64(06):490-493, discussion 493-494

9 Lobatto DJ, de Vries F, Zamanipoor Najafabadi AH, et al. Preoperative risk factors for postoperative complications in endoscopic pituitary surgery: a systematic review. Pituitary 2018;21(01):84-97

10 Nishioka H, Haraoka J, Ikeda Y. Risk factors of cerebrospinal fluid rhinorrhea following transsphenoidal surgery. Acta Neurochir (Wien) 2005;147(11):1163-1166, discussion 1166

11 Dlouhy BJ, Madhavan K, Clinger JD, et al. Elevated body mass index and risk of postoperative CSF leak following transsphenoidal surgery. J Neurosurg 2012;116(06):1311-1317

12 Ivan ME, Iorgulescu JB, El-Sayed I, et al. Risk factors for postoperative cerebrospinal fluid leak and meningitis after expanded endoscopic endonasal surgery. J Clin Neurosci 2015;22(01):48-54
13 Boling CC, Karnezis TT, Baker AB, et al. Multi-institutional study of risk factors for perioperative morbidity following transnasal endoscopic pituitary adenoma surgery. Int Forum Allergy Rhinol 2016;6(01):101-107

14 Karnezis TT, Baker AB, Soler ZM, et al. Factors impacting cerebrospinal fluid leak rates in endoscopic sellar surgery. Int Forum Allergy Rhinol 2016;6(11):1117-1125

15 Senior BA, Ebert CS, Bednarski KK, et al. Minimally invasive pituitary surgery. Laryngoscope 2008;118(10):1842-1855

16 Jakimovski D, Bonci G, Attia M, et al. Incidence and significance of intraoperative cerebrospinal fluid leak in endoscopic pituitary surgery using intrathecal fluorescein. World Neurosurg 2014;82 (3-4):e513-e523

17 McLaughlin N, Martin NA, Upadhyaya P, et al. Assessing the cost of contemporary pituitary care. Neurosurg Focus 2014;37(05):E7

18 Hanauer DA, Mei Q, Law J, Khanna R, Zheng K. Supporting information retrieval from electronic health records: a report of University of Michigan's nine-year experience in developing and using the Electronic Medical Record Search Engine (EMERSE). J Biomed Inform 2015;55:290-300

19 Ciric I, Ragin A, Baumgartner C, Pierce D. Complications of transsphenoidal surgery: results of a national survey, review of the literature, and personal experience. Neurosurgery 1997;40 (02):225-236, discussion 236-237

20 Sun I, Lim JX, Goh CP, et al. Body mass index and the risk of postoperative cerebrospinal fluid leak following transsphenoidal surgery in an Asian population. Singapore Med J 2018;59(05): 257-263

21 Lundeen EA, Park S, Pan L, O’Toole T, Matthews K, Blanck HM. Obesity prevalence among adults living in metropolitan and nonmetropolitan counties - United States, 2016. MMWR Morb Mortal Wkly Rep 2018;67(23):653-658

22 Lam G, Mehta V, Zada G. Spontaneous and medically induced cerebrospinal fluid leakage in the setting of pituitary adenomas: review of the literature. Neurosurg Focus 2012;32(06):E2

23 Horowitz G, Fliss DM, Margalit N, Wasserzug O, Gil Z. Association between cerebrospinal fluid leak and meningitis after skull base surgery. Otolaryngol Head Neck Surg 2011;145(04):689-693

24 Chern A, Hunter JB, Bennett ML. Cost analysis of cerebrospinal fluid leaks and cerebrospinal fluid leak prevention in patients undergoing cerebellopontine angle surgery. Otol Neurotol 2017; 38(01):147-151 